RAD Conference Proceedings, vol. 3, pp. 81-84, 2018

ISSN 2466-4626 (online) | DOI: 10.21175/RadProc.2018.17

www.rad-proceedings.org

\title{
CORRELATION OF RADIATION AND METEOROLOGICAL PARAMETERS DURING ENVIRONMENTAL RADIATION MONITORING IN PUBLIC COMPANY “NUCLEAR FACILITIES OF SERBIA”
}

\author{
Vesna Radumilo*, Ivan Knežević, Dalibor Arbutina \\ Public Company “Nuclear Facilities of Serbia”, Vinča, Serbia
}

\begin{abstract}
Public Company "Nuclear Facilities of Serbia" is the only nuclear operator in Serbia. Under the radiation safety and radiation protection measures of people and environment, Public Company conducts the environmental radiation monitoring around nuclear facilities. Monitoring also includes relevant meteorological measurements at the micro-location. This paper shows the correlation between the change of ambient gamma dose rate equivalent in the air and meteorological parameters: precipitation and the relative humidity in air. All the measurements were taken at the site of a meteorological tower on 114 meters above sea level, in the vicinity of nuclear facilities. Monthly values of relative humidity of the air and intense rainfall were obtained during 2017. The analysis of this relation clearly shows the impact of the intense rain and the relative humidity of the air on the ambient gamma dose rate equivalent. Calculated Pearson's correlation coefficient shows the degree of the above-mentioned dependence.
\end{abstract}

Key words: Radiation monitoring, environment, ambient gamma dose, nuclear facilities

\section{INTRODUCTION}

Humans are exposed to a different kind of naturally occurring radiation. This includes radiation from outer space as well as radiation from natural sources on Earth. Naturally occurring radiation sources provide $85.5 \%$ of the average radiation dose received by the population and are mainly due to cosmic radiation, terrestrial radiation and radon [1]. Radon is a naturally-occurring gas produced in the radioactive decay chains of uranium and thorium.

Due to exhalation process the atmospheric concentrations of radon $\left({ }^{222} \mathrm{Rn}\right)$, thoron $\left({ }^{220} \mathrm{Rn}\right)$ and their daughters are affected by the meteorological parameters specific to the planetary boundary layer, such as air temperature, atmospheric pressure, wind speed, precipitations and relative humidity in the air $[2,3]$. The cosmic radiation and natural radioactivity in soil are the main contributors to the external gamma dose, whereas Chernobyl accident has a small contribution as well.

Public company "Nuclear Facilities of Serbia" (PC NFS) is the only institution in the Republic of Serbia responsible for managing nuclear facilities in a safe and secure manner, therefore implementing the environmental radiation monitoring around nuclear facilities.

PC NFS operates the research nuclear reactor (RA), which is in the preparation for decommissioning activities, experimental zero power nuclear reactor (RB), two old radioactive waste storage facilities
(Hangar H1 and Hangar H2) with the nuclear license for the final shut-down, two new radioactive waste storage facilities in operation (Hangar $\mathrm{H}_{3}$ and secure storage SS), waste processing facility in preparation for trial-run and closed uranium mine Gabrovnica in eastern Serbia.

The complete environmental radiation monitoring around nuclear facilities in the PC NFS includes the examination of the level of external radiation by the continuous ambient gamma dose rate equivalent measurements in the air and ambient gamma dose equivalent measurements in the air, the relevant meteorological measurements and the observations at micro-location, radioactive contamination levels control in different media such as air, precipitations, soil, surface water, river sediment, drinking water, groundwater, wastewater, foodstuff and bio-indicators, as well as the mathematical modeling dispersion of air pollutants in the boundary layer of the atmosphere $[4,5,6]$.

When pollutants get into the atmosphere they are being spread by the wind transport, atmospheric diffusion, dry and wet deposition, resuspension and chemical transformations. Concentrations of pollutants in the atmosphere can be obtained by measuring through adequate monitoring network or by mathematical modeling. The variation in values of the environmental gamma dose rate equivalent can seriously interfere with the monitoring of the unexpected release of the radioactivity from nuclear facilities [7]. The objective of the presented work is to assess the impact of the weather parameters on the

*vesna.radumilo@nuklearniobjekti.rs 
V. Radumilo et al., Correlation of radiation and meteorological parameters..., RAD Conf. Proc., vol. 3, 2018, 81-84

radiation background in the vicinity of nuclear facilities in order to quickly detect radiation released due to operation of these facilities.

\section{MEASUREMENTS AND METHODS}

Continuous ambient gamma dose rate equivalent measurements in the air in the vicinity of nuclear facilities are performed at five locations around the nuclear facilities and at one referent location away from the nuclear facilities in the village of Vinča, which is a part of the system of early warning of emergency at the state level. The presented results in this paper were obtained at the measuring location "Meteorological tower" which consists of the automated meteorological station and the gamma dose rate monitor. Continuous gamma dose rate measurements were obtained by multifunctional gamma dose rate monitor with two compensated Geiger-Müller probes. Measuring range of the probes covers the interval from the background level $(50 \mathrm{nSv} / \mathrm{h})$ up to accidental levels $(1 \mathrm{~Sv} / \mathrm{h})$. The calibration of the dose rate monitor was carried out in the certified laboratory, in the field of gamma radiation of sources ${ }^{137 \mathrm{Cs}}$ and ${ }^{60} \mathrm{Co}$, according to IAEA SRS 16 standard [8]. The dose rate measurement uncertainty is below $5 \%$, which represents combined standard uncertainty with the level of confidence of $95 \%(\mathrm{k}=2)$.

Meteorological parameters, i.e. values of the precipitation level and the relative humidity in the air, were obtained by automated meteorological station set up on the meteorological tower of the $40 \mathrm{~m}$ of height, positioned at $114 \mathrm{~m}$ above the sea level. The automated sensors are placed on several levels at the tower: at $1 \mathrm{~m}$, $2 \mathrm{~m}, 10 \mathrm{~m}$ and $40 \mathrm{~m}$, as shown on the scheme in Fig. 1. The dose rate monitor is positioned at $1.3 \mathrm{~m}$ above the grass surface, just next to the meteorological tower. The measuring range of the tipping bucket rain gauge, used for the precipitation level measurements, with the resolution of $0.1 \mathrm{~mm}$. The measuring range of the air humidity sensor is from $0.8 \%$ up to $100 \%$ of relative humidity in the air, with the resolution of $1 \%$. The meteorological measurements and observations were conducted in accordance with the World Meteorological Organization guide [6].

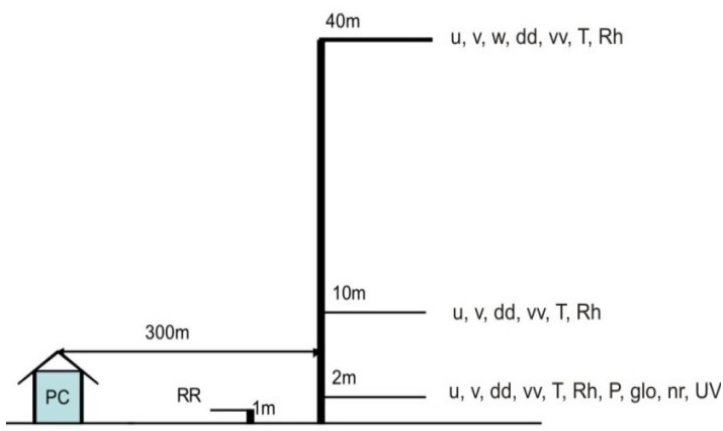

Figure 1. Scheme of measurements at meteorological tower $(u, v, w w$ - wind speed components, $d d, v v$ - wind direction, $T$ - air temperature, $R h$ - relative humidity in the air,

$P$ - air pressure, $U V$ - ultraviolet radiation, glo - global solar radiation, $n r$ - radiation balance, $R R$ - precipitations, $P C$ - personal computer)

\section{RESUlTS AND DISCUSSION}

Obtained results of continuous gamma dose rate equivalent measurements in the air and measurements of the precipitations and the relative humidity of air at micro-location at the measuring point "Meteorological tower" indicated the existence of the correlation between radiological and meteorological parameters. Based on the sufficient data, the scatter diagram showing the dependence of the mean daily values of the dose rate and the precipitation levels for fall 2017, has been created and presented in Fig. 2.

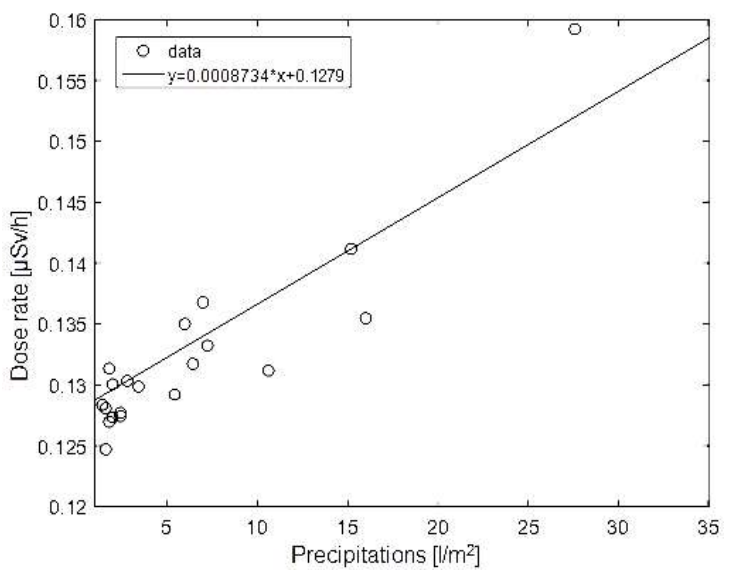

Figure 2. Dependence of the mean daily values of the dose rate and the precipitation levels for the fall 2017.

Assuming the linear relationship between dose rate and meteorological variables, Pearson correlation coefficients have been computed, as presented in Table 1.

Table 1. The Pearson's correlation coefficients

\begin{tabular}{|c|c|c|}
\hline \multirow{2}{*}{$\begin{array}{c}\text { Month in year } \\
2017\end{array}$} & \multicolumn{2}{|c|}{ Pearson correlation coefficient } \\
\cline { 2 - 3 } & Precipitations & $\begin{array}{c}\text { Relative } \\
\text { humidity in air }\end{array}$ \\
\hline January & 0.23 & -0.12 \\
\hline February & 0.34 & 0.39 \\
\hline March & 0.69 & 0.31 \\
\hline April & 0.56 & 0.39 \\
\hline May & 0.48 & 0.31 \\
\hline June & 0.51 & -0.01 \\
\hline July & 0.47 & 0.01 \\
\hline August & 0.45 & 0.02 \\
\hline September & 0.65 & 0.01 \\
\hline October & 0.73 & 0.23 \\
\hline November & 0.68 & 0.42 \\
\hline December & 0.52 & 0.23 \\
\hline
\end{tabular}

Pearson's correlation coefficient quantifies the degree of the dependence of one physical measure on the other, measuring the strength and the direction of a linear relationship. It takes values between -1 and +1 inclusive, where the positive values indicate the increase of values for both parameters, whereas negative values indicate the decrease of the values of one parameter for the increase of the values of the other one. 
V. Radumilo et al., Correlation of radiation and meteorological parameters..., RAD Conf. Proc., vol. 3, 2018, 81-84

The following criteria were used for Pearson's correlation coefficient: uncorrelated (for a value that is between -0.09 and 0.09), low correlated (for a value that is between -0. 3 and -0.1 or between 0.1 and 0.3 ), medium correlated (for a value that is between -0.5 and -0.3 or between 0.3 and 0.5 ) and strong correlated (for a value that is between -1.0 and -0.5 or between 0.5 and 1.0) [3].

For the given results in Table 1 , it is clearly seen that the dominant correlation between gamma dose rate equivalent and the level of precipitations is strong correlation for the following months in 2017: March, April, June, September, October, November and December. The medium correlation was obtained for February, May, July and August, where the Pearson's correlation coefficient values for three out of four of these months were close to the values for strong correlation. Low correlation was found for January 2017.

In the case of relationship between dose rate and relative humidity in the air, there was no correlation in June, July, August and September; low correlation was obtained for January, October and December, where medium one was calculated for February, March, April, May and November 2017.

In order to show the correlated changes of the values of dose rate and meteorological variables, the mean daily values of the gamma dose rate equivalent in the air and the relative humidity of the air, as well as the total daily values of precipitations, are presented in Fig.3 for November, the rainiest month in 2017.

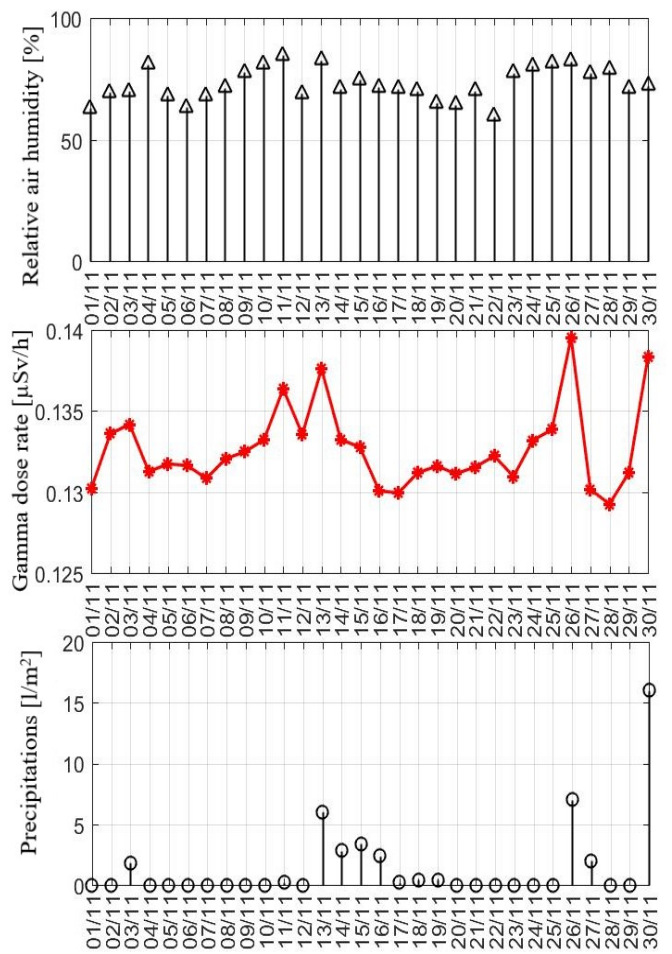

Figure 3. Gamma dose rate equivalent and meteorological variables, November 2017.

\section{CONCLUSION}

In accordance with general requirements for the safety and emergency preparedness arrangements around nuclear facilities, releases of radioactive materials from nuclear facilities and their concentrations in the environment shall be effectively monitored. Provisions will be made to carry out radiological and meteorological measurements, as well as the correlation between their values $[4,5]$.

The obtained Pearson coefficients regarding dependence between radiological and meteorological parameters definitely show the existence of the relationship between dose rate and meteorological parameters, with prevailing medium and strong correlation between dose rate and level of precipitation. Since the relative humidity is usually correlated with the precipitation, it is expected that the dose rate correlates with the humidity.

The fluctuation of the ambient radiation field is the consequence of the atmospheric deposition and wash of the radionuclides. The micro-layer of atmospheric deposition is deposited both on the detector's surface as well as on the ground surface, which immediately triggers the instrument's response.

Radon and thoron diffusion process and exhalation rate from the ground surface are affected by the concentration of their precursors in the ground, properties of the soil and meteorological parameters, which also gives rise to the value of the radiation field.

From the radiation safety and protection against ionizing radiation point of view, it is very important to understand the impact of all factors that can lead to an increase in the value of radiation parameters, in order to unambiguously determine whether it is a potential accident or not.

\section{REFERENCES}

1. Sources and Effects of Ionizing Radiations, vol. 1, UNSCEAR Report (A/55/46), UNSCEAR, New York (NY), USA, 2000

Retrieved from:

http://www.unscear.org/docs/publications/2000/UNS CEAR 2000 Report Vol.I.pdf

Retrieved on: May 20, 2018

2. C. R Hosler, "Meteorological effects on atmospheric concentrations of radon (Rn222), $\mathrm{RaB}(\mathrm{Pb} 214)$, and $\mathrm{RaC}(214 \mathrm{Bi})$ near the ground," American Meteorological Society, Feb. 1966.

DOI: $10.1175 / 1520-$ 0493(1966)094<0089:MEOACO>2.3.CO;2

3. E. Simion, I. Mihalcea, F. Simion, C. Pacuraru, "Evaluation Model of Atmospheric Natural Radioactivity Considering Meteorological Variables," Rev. Chim., vol. 63, no. 12, pp. 1251 - 1256, 2012. Retrieved from: http://revistadechimie.ro/pdf/SIMION \%20E.pdf\%2012\%2012.pdf; Retrieved on: Apr. 29, 2018

4. Vlada Republike Srbije. (28.9.2012). Sl. Glasnik br 36/o9 i br. 93/12. Zakon o zaštiti od jonizujućih zračenja i o nuklearnoj sigurnosti. (Government of the Republic of Serbia. (Sep. 28, 2012). Official Gazette no. 36/o6 and no. 93/12. Law on protection from the ionizing radiation and nuclear safety.) 
V. Radumilo et al., Correlation of radiation and meteorological parameters..., RAD Conf. Proc., vol. 3, 2018, 81-84

Retrieved from: http://www.srbatom.gov.rs/srbatom/d oc/vazeca akta/ZAKON O ZASTITI OD JONIZUJU CIH ZRACENJA I NUKLEARNOJ SIGURNOSTISLGL-36-09-I-93-12-LAT.pdf;

Retrieved on: May 15, 2018

5. Agencija za zaštitu od jonizujućih zračenja i nuklearnu sigurnost Srbije. (Dec. 21, 2011). Br 97/11. Pravilnik o monitoringu radioaktivnosti. (Serbian Radiation Protection and Nuclear Safety Agency. (Dec. 21, 2011). No. 97/11. Rulebook on Radioactivity Monitoring. Retrieved from:

http://www.imrs.rs/!uploads/PRAVILNIK\%20O\%20M ONITORINGU\%2ORADIOAKTIVNOSTI\%2O(Sl.\%20gl asnik\%20RS,\%20br.\%2097-2011)\%20-\%20LAT.pdf

Retrieved on: May 15, 2018

6. Guide to Meteorological Instruments and Methods of Observations, WMO-No.8, WMO, Geneva, Switzerland, 2008.

Retrieved from: https://library.wmo.int/pmb ged/wm o 8 en-2012.pdf Retrieved on: May 10, 2018

7. J. F. Mercier et al., "Increased environmental gammaray dose rate during precipitation: a strong correlation with contributing air mass," J. Environ. Radioact., vol. 100, no. 7, pp. 527 - 533, Jul. 2009.

DOI: 10.1016/j.jenvrad.2009.03.002

PMiD: 19403214
8. Calibration of Radiation Protection Monitoring Instruments, IAEA SRS No. 16, IAEA, Vienna, 2000.

Retrieved from: https://wwwpub.iaea.org/MTCD/Publications/PDF/Po74 scr.pdf; Retrieved on: Apr. 29, 2018

9. V. Radumilo, I. Knežević, D. Žarković, D. Arbutina, "Korelacija radijacionih parametara i količine padavina prilikom monitoringa radioaktivnosti u okolini nuklearnih objekata," y Zbornik radova XXIX Simpozijuma (DZZSCG, 2017), Srebrno jezero, Srbija, pp. 2017, 37-44.

(V. Radumilo, I. Knežević, D. Žarković, D. Arbutina, "Correlation of radiation parameters and the level of precipitations during monitoring of radioactivity in the vicinity of nuclear facilities" in Proc $29^{\text {th }}$ Symposium, Society for Radiation Protection of Serbia and Montenegro (DZZSCG, 2017), Srebrno jezero, Serbia, 2017, pp. $37-44$.

Retrieved from:

https://mail.ipb.ac.rs/ centar3/radovi171020/2017 C No3-

04 Zbornik XXIX Simpozijum DZZ SCG 2017.pdf; Retrieved on: May 10, 2018 